\title{
Morte do duplo, morte de si: o suicídio em três narrativas góticas do século 19
}

\section{Death of the double, death of the self: suicide in three gothic narratives from the 19th century}

\section{Muerte del doble, muerte de sí: el suicidio en tres narrativas góticas del siglo 19}

\author{
iD Willian André \\ Universidade Estadual do Paraná (UNESPAR). Campo Mourão, Paraná, Brasil. \\ E-mail: willianandreh@hotmail.com
}

\section{iD) Ana Paula Oliveira}

Professora de Educação Infantil. Campo Mourão, Paraná, Brasil. E-mail: aninha_ubi@hotmail.com

Resumo: este artigo tem por objetivo analisar como o suicídio é representado nas narrativas $O$ retrato de Dorian Gray, de Oscar Wilde, O estranho caso de Dr. Jekyll e mr. Hyde, de robert louis stevenson, e "William Wilson", de Edgar Allan Poe, considerando que todas as três apresentam situações sobrenaturais, relacionadas à figura do duplo. Além de observar essa profunda relação entre a morte voluntária e o duplo em termos de narrativa, procuraremos também desenvolver uma discussão mais contextual sobre o tema do suicídio no século 19. O referencial teórico será fornecido por Bravo (2005) e Benyon-Payne (2015), entre outros.

Palavras-chave: Suicídio. Duplo. Narrativas góticas.

Abstract: This article aims at analyzing how suicide is represented in The Picture of Dorian Gray, by Oscar Wilde, The Strange Case of Dr. Jekyll and Mr. Hyde, by Robert Louis Stevenson, and "William Wilson", by Edgar Allan Poe, considering that all three of them present supernatural situations linked to the image of the double. Besides dealing with this deep relation 
between voluntary death and the double at narrative level, we also seek to develop a contextual discussion about suicide in 19th century. Theoretical foundations are given, among others, by Bravo (2005) and Benyon-Payne (2015).

Keywords: Suicide. Double. Gothic Fiction.

Resumen: Este artículo tiene por objetivo analizar cómo el suicidio se representa en las narrativas El retrato de Dorian Gray, de Oscar Wilde, El extraño caso del doctor Jekyll y el señor Hyde, de Robert Louis Stevenson, y "William Wilson", de Edgar Allan Poe, considerando que todas las tres presentan situaciones sobrenaturales, relacionadas con la figura del doble. Además de observar esa profunda relación entre la muerte voluntaria y el doble a nivel de narrativa, procuraremos también desarrollar una discusión más contextual sobre el tema del suicidio en el siglo 19. El referencial teórico, entre otros, será proporcionado por Bravo (2005) y Benyon-Payne (2015).

Palabras clave: Suicidio. Doble. Narrativas góticas.

Submetido em 13 de maio de 2019.

Aceito em 22 de agosto de 2019.

Publicado em 24 de março de 2020. 
Morte do duplo, morte de si: o suicídio em três narrativas góticas do século 19 Willian André • Ana Paula Oliveira

Realizar um estudo sobre o duplo em narrativas como o romance $O$ retrato de Dorian Gray (1890), de Oscar Wilde, a novela $O$ estranho caso de Dr. Jekyll e Mr. Hyde (1886), de Robert Louis Stevenson, e o conto "William Wilson" (1839), de Edgar Allan Poe, pode parecer uma proposta um tanto óbvia, já que as obras em questão são bem conhecidas, em grande parte, por tratarem do tema do duplo. A ideia aqui, no entanto, não é tanto focar nesse tema, mas sim na relação que se estabelece entre ele e o suicídio nas três narrativas. Se podemos afirmar que o duplo é o elemento que atua como desencadeador do sobrenatural nesses textos de Wilde, Stevenson e Allan Poe, também podemos observar que a única forma encontrada pelos personagens para eliminar o sobrenatural, nos três casos, é por meio da morte desse outro, que também é o eu.

David Roas (2001, p. 9) desenvolve a teoria de que o elemento fantástico ${ }^{1}$ em uma narrativa representa certa forma de "ameaça", pois, ao inserir em sua estrutura algum fato ou personagem sobrenatural, põe em risco a validade daquilo que se costuma chamar de "realidade" a partir de uma interpretação pautada na lógica. Em outras palavras, quando um texto se abre à possibilidade de que algo inexplicável pelo raciocínio lógico possa existir, isso faz com que a realidade que se tinha por certa adentre um terreno nebuloso de dúvida e incerteza. A eliminação do duplo por meio do suicídio, nesse sentido, assume um aspecto paradoxal, porque restabelece a normalidade (uma vez que a "ameaça" do elemento sobrenatural é suprimida), mas ao mesmo tempo impede o sujeito da ação de gozar desse estado de normalidade, já que, para restabelecê-la, precisa dar cabo da própria vida.

Conforme afirmamos acima, a popularidade do material que compõe nosso corpus de análise é notória. Além de serem obras escritas por autores muito representativos das literaturas de língua inglesa do século 19, elas se inscrevem também em certo revival da narrativa gótica que o mesmo século observou em, pelo

\footnotetext{
1 Como se sabe, existem muitas abordagens teóricas sobre o elemento fantástico e algumas delas são conflituosas. Neste artigo, nos furtamos a abordar tais teorias, pois isso demandaria muito fôlego e nos faria desviar de nosso propósito. É por esse motivo que preferimos empregar a expressão "sobrenatural", que, sob nossa percepção, tende a gerar menos conflito teórico. Ainda assim, entendemos que as três narrativas a compor nosso corpus se projetam para dentro daquilo que teoricamente se entende como "fantástico" (mesmo no caso da narrativa de Stevenson, que fornece um suposto embasamento científico para a erupção do elemento sobrenatural).
} 
Morte do duplo, morte de si: o suicídio em três narrativas góticas do século 19

menos, dois momentos distintos: no caso de Allan Poe, na esteira dos românticos europeus, porém contando com adaptações mais apropriadas ao contexto social e espacial norte-americano (cf. FlSHER, 2004, p. 77-78); e, no caso de Stevenson e Wilde, no contexto da Era Vitoriana tardia.

A respeito do gótico, não nos estenderemos aqui na composição de um panorama histórico ou de uma caracterização, limitando-nos a registrar que estamos pensando em Wilde, Stevenson e Poe a partir de definições e características como aquelas apresentadas por Cuddon (1998, p. 356), Benyon-Payne (2015) e Fisher (2004). Considerando especificamente o gótico romântico, talvez pudéssemos ter incluído em nosso estudo o romance Frankenstein (1818), de Mary Shelley, já que há a possibilidade de entender a Criatura/Monstro como um duplo de Victor (BENYON-PAYNE, 2015, p. 130-131) - ademais, ao final da narrativa, a Criatura se dirige solitária para as paisagens isoladas do polo norte, para construir sua pira funerária e, nela, tirar a própria vida (SHELLEY, 2017, p. 225-226). Todavia, entendemos que a relação que se estabelece entre o Monstro e Frankenstein, em termos de duplo, se distancia consideravelmente da relação que abordaremos aqui.

Quanto ao duplo, nossas considerações são guiadas pelo estudo de Nicole Fernandez Bravo (2005), que é autora de um verbete sobre o tema no Dicionário de mitos literários, organizado por Pierre Brunel. O duplo se constitui mito no início das civilizações e continua a ser (re)trabalhado e ressignificado em diversas manifestações literárias até hoje. No século 19, que compõe nosso contexto de estudo, um dos exemplos mais conhecidos é o romance de Dostoiévski intitulado justamente $O$ duplo (1846). Em uma visada mais abrangente, o fenômeno em questão pode ser identificado em diversas narrativas fundantes da cultura ocidental, desde Caim e Abel, na Bíblia, passando por Narciso e seu reflexo no lago, na Mitologia Grega, até Janus e suas duas faces, na Mitologia Romana. A vitalidade do tema se faz notável se considerarmos que, no século 20, ainda o encontramos sob o trato de muitas produções literárias expressivas, passando por autores como Franz Kaf- 
Morte do duplo, morte de si: o suicídio em três narrativas góticas do século 19 Willian André • Ana Paula Oliveira

ka, Jorge Luis Borges e Guimarães Rosa, até o recente romance $O$ homem duplicado (2002), de José Saramago.

Em seu estudo, Nicole Fernandez Bravo (2005) propõe um percurso histórico, contemplando exemplificações literárias e interpretações diversas. Nesse percurso, nos interessa principalmente a abordagem da autora sobre o século 19, quando a interpretação da subjetividade humana "força ao abandono progressivo do postulado da unidade da consciência, da identidade de um sujeito, única e transparente" (BRAVO, 2005, p. 267). A partir daí, cada vez mais se desenvolve um entendimento do duplo enquanto manifestação do heterogêneo, de uma identidade dividida: "Quanto mais avançamos no século XIX, mais chega ao primeiro plano (...) a representação do dilaceramento vivido pelo eu até em seus aspectos patológicos" (BRAVO, 2005, p. 276). O patológico, aqui, pode dizer respeito a diversas condições da alma que são, a partir de finais do século 19 e início do 20, cada vez mais estudadas pela então recém-surgida ciência da psicologia - e, entre seus desdobramentos, pela psicanálise.

Independente desses processos de patologização, de qualquer forma, parece nítido que a grande questão que o duplo literário procura representar ao longo do século 19 (e mesmo depois) é aquela relacionada ao tormento da descoberta de que o ser humano possui uma identidade fragmentada. Atualmente, pode parecer óbvia a afirmação de que somos todos portadores de identidades cindidas, heterogêneas, mas nem sempre foi assim: conforme registra Bravo (2005, p. 276), é principalmente no século 19 que se passa a alimentar uma consciência sobre a fragmentação identitária.

É nesse cenário que encontramos a primeira narrativa a compor nosso corpus'. "William Wilson" inicia com o narrador homônimo enfatizando a torpeza e mediocridade de sua alma, se acusando constantemente e fazendo várias menções à sua "perversidade", "vergonha", e a seus "anos de miséria e crime" (cf. POE,

2 Ainda que "William Wilson", O estranho caso de Dr. Jekyll e Mr. Hyde e O retrato de Dorian Gray sejam textos muito conhecidos, nos prestaremos a apresentar algumas informações sobre seus enredos, a fim de fundamentar a análise. 
Morte do duplo, morte de si: o suicídio em três narrativas góticas do século 19

2008 , p. 234) - estratégia recorrente em Poe, que pode ser observada também, por exemplo, em "O gato preto" e "O coração delator". A partir desse auto-rebaixamento inicial, ele passa a relatar os eventos que o trouxeram ao presente estado.

Seu relato inicia pela infância na escola e envolve um segundo personagem: no mesmo dia em que Wilson dá início às aulas, aparece um aluno com o mesmo nome que o seu e com outras semelhanças que os igualavam em praticamente tudo: o jeito de agir, andar, vestir (as roupas são sempre iguais). O jeito de falar também é o mesmo, se bem que o segundo William Wilson fale sempre com uma voz mais baixa. Para completar, até a data de nascimento, dia 19 de janeiro de 1813, é a mesma. Naturalmente, a situação exerce influência sobre o humor do personagem:

\begin{abstract}
Logo no dia da minha chegada, apresentou-se também o outro William Wilson; isso foi o suficiente para que eu sentisse contra ele certa má vontade, visto que daí em diante ouviria pronunciar o dobro das vezes aquelas sílabas que eram o tormento dos meus ouvidos. Constantemente o teria junto de mim, porque sua vida, no arrastar dos trabalhos e divertimentos do colégio, frequentemente seria confundida com a minha. E tudo isso me levava a desgostar-me cada vez mais do meu nome (POE, 2008, p. 241).
\end{abstract}

O tema do duplo fica escancarado, portanto, desde o início do conto. Apesar de chamado algumas vezes na narrativa de "gêmeo" ou "sósia", há uma sugestão muito grande de que a presença do segundo Wilson envolve algum elemento sobrenatural, já que as semelhanças se colocam muito além das meras coincidências. Não há qualquer explicação no conto sobre a origem dessa réplica do narrador, não há nenhuma sugestão explícita de que se trate de algum tipo de alegoria e tampouco alguma informação concreta o suficiente para admitirmos que apenas o William Wilson original é capaz de ver (e interagir com) seu duplo. Mas, conforme a narrativa avança, fica uma impressão cada vez maior de que se trata de uma projeção da consciência do protagonista. 
Morte do duplo, morte de si: o suicídio em três narrativas góticas do século 19 Willian André • Ana Paula Oliveira

Depois de finalizar as atividades na escola, e tendo se tornado já adulto, o William Wilson original mergulha cada vez mais em "vícios" (são comentados explicitamente, no conto, o vício na bebida e o vício no jogo), e o duplo continua a acompanhá-lo, aparecendo sempre em situações inusitadas - sempre em situações em que as devassidões estão atingindo seus extremos -, reprovando as atitudes do protagonista. Cada vez mais, o segundo Wilson parece se tornar a consciência encarnada do narrador do conto. A esse respeito, Bravo observa que "aquele que se desdobrou (duplicou) cria para si a ilusão de agir sobre o exterior, quando na verdade não faz mais que objetivar seu drama interior" (BRAVO, 2005, p. 267).

O personagem principal inicia viagens e percorre vários países da Europa numa tentativa de se livrar de seu flagelo. O desfecho da narrativa se dá em Roma, durante o carnaval, "num baile de máscaras dado no palácio do duque di Broglio" (POE, 2008, p. 252). Nesse contexto, como é hábito seu, Wilson está engajado na bebida e no jogo de cartas, e, por meio de trapaças, leva um de seus adversários à ruína financeira. É nesse momento que surge, uma vez mais, William Wilson Segundo. Atordoado por sua perfídia de jogador ter sido exposta ao público por seu duplo, o protagonista o convoca para estar com ele a sós em uma antecâmera. Ali, inicia-se uma luta de espadas:

O combate não durou muito. Exaltado como estava, nervoso e cheio de ódio, sentia meu braço forte e firme como nunca. Em poucos minutos fi-lo recuar até a parede e, uma vez ali, vendo-o impotente para defender-se, trespassei-Ihe o peito sucessivas vezes com selvagem ferocidade (POE, 2008, p. 253).

Logo após matar seu oponente, Wilson percebe que está sozinho no cômodo. Dirigindo-se a um espelho que antes Ihe passara despercebido, vê seu próprio rosto, pálido, e o corpo cheio de ferimentos. Diante da própria imagem, uma vez mais confundida com a imagem daquele que o perseguira durante toda a vida, ele proclama: 
Morte do duplo, morte de si: o suicídio em três narrativas góticas do século 19

Venceste e eu pereço. Mas daqui para frente também tu estarás morto. Morreste para o mundo, para o céu e para a esperança! Existias em mim. Olha bem agora para a minha morte, e nessa imagem, que é a tua, verás o teu próprio suicídio! (POE, 2008, p. 253).

Conforme Bravo, o diálogo/monólogo que encerra o conto "põe fim à ilusão de Wilson que até o último momento não quer compreender que tentou matar a própria consciência, mas que esta acabou sendo mais forte" (BRAVO, 2005, p. 276). Sobre o duplo do narrador ter possuído efetivamente uma existência concreta, de carne e osso, não saberemos responder. Mas, ao final, a impressão de que se tratava da consciência do personagem se confirma, e, tentando matá-la, William Wilson acaba por tirar a própria vida.

Até certo ponto, esse é o modelo que será adotado nas outras duas narrativas de nosso corpus. O estranho caso de Dr. Jekyll e Mr. Hyde, novela conhecida popularmente no Brasil pelo título "O médico e o monstro", conta a história de Dr. Henry Jekyll, um cidadão renomado e bem-conceituado no contexto da Era Vitoriana. A narrativa se desenvolve em um clima policial, de investigação, criando uma série de reviravoltas de enredo, mas mantendo como eixo central a dualidade do caráter do protagonista da novela. Conforme palavras do próprio Dr. Jekyll:

[...] o pior dos meus defeitos era uma certa disposição impaciente para o divertimento, como a que fizera a felicidade de muitos, mas com a qual achei difícil conciliar meu imperioso desejo de manter a cabeça erguida e ter uma postura mais séria do que a média. Em consequência disso, passei a ocultar meus prazeres, e quando, após anos de reflexão, comecei a olhar ao redor e a avaliar meu progresso e minha posição no mundo, já estava seriamente comprometido com uma vida dupla. Muitos homens teriam até se vangloriado de tais deslizes, ao passo que eu, de minha parte, me sentia culpado; e considerando os elevados padrões que estabelecera para mim mesmo, eu os julgava e escondia com uma vergonha quase mórbida. Por 
Morte do duplo, morte de si: o suicídio em três narrativas góticas do século 19

conseguinte, era a natureza exigente de minhas aspirações, mais do que qualquer degradação em meus defeitos, o que me levava a ser o que eu era, e, cavando uma trincheira ainda mais profunda do que costumava fazer a maioria dos homens, eu separava em mim essas esferas de ação do bem e do mal que dividem e compõem a natureza dual de todo homem. (...) A cada dia, e a partir dos dois lados da minha inteligência, o moral e o intelectual, fui me encaminhando aos poucos para perto daquela verdade cuja descoberta parcial havia me condenado a tão pavorosa ruína: a de que o homem não é verdadeiramente um, mas verdadeiramente dois (STEVENSON, 2011 b, p. 225-226).

O trecho dá evidências suficientes para se pensar a questão do duplo. Jekyll não se contenta em apenas cultivar uma consciência alarmante a respeito de sua situação moral/psicológica e acaba colocando em prática seus conhecimentos científicos: o personagem desenvolve uma espécie de poção que, ao ser ingerida, o transforma em outra pessoa. Esse outro concentra todos os seus sentimentos e intenções mais devassas, justamente aquilo que sua persona social precisava suprimir para que ele se mantivesse de acordo com os padrões sociais vigentes. Trata-se aqui, conforme Bravo, de um choque entre desejo e personalidade: “o heterogêneo é, numa de suas componentes, a dualidade do ser: o sujeito de desejo entra em choque com a personalidade, imagem imposta pela sociedade" (BRAVO, 2005, p. 276). Além disso, segundo Jorge Luis Borges (2002, p. 382), a narrativa lida com a questão da esquizofrenia, mesmo antes de o próprio termo ser cunhado. O resultado dessa metamorfose é o surgimento físico/concreto do duplo do personagem: Edward Hyde, aquele que terá a liberdade de cometer, ao longo da narrativa, todo tipo de ações ilícitas, sem que sua versão mais nobre - Dr. Jekyll - seja incriminada.

Se no caso de "William Wilson" o espelho foi o elemento revelador da verdadeira identidade do duplo do protagonista, utilizado apenas no desfecho da situação, no caso de "O médico e o monstro" o mesmo objeto constitui um elemento de reconhecimento 
Morte do duplo, morte de si: o suicídio em três narrativas góticas do século 19 Willian André • Ana Paula Oliveira

inicial do duplo. Após Jekyll ingerir a poção e tornar-se Hyde pela primeira vez, ele se olha no espelho e constata:

\section{[...] quando olhei para aquela horrível figura no espelho, estava} consciente de não sentir repugnância nenhuma, e sim o impulso de Ihe dar as boas-vindas. Aquele também era eu. Parecia natural e humano. A meus olhos, exibia a imagem de um espírito mais vivaz. Parecia mais exato e inteiro do que o imperfeito e dividido semblante que eu costumava chamar de meu (STEVENSON, 2011b, p. 230).

Há aqui, portanto, uma diferença com relação à primeira narrativa apresentada. O reconhecimento do duplo no espelho não acarreta o estranhamento que define as linhas finais de "William Wilson", mas sim um sentimento de "boas-vindas" por parte de Dr. Jekyll, o cidadão de bem, a seu outro maligno, o grotesco Edward Hyde. Como a novidade tende a se tornar hábito, o protagonista se acostuma à vida dupla e, ao longo da narrativa, Hyde expressa concretamente as maldades de Jekyll - cometendo, no ápice de tais maldades, até mesmo um assassinato -, sem que a origem desse mal possa ser rastreada até a figura do nobre cidadão vitoriano, posto que os dois personagens não mantêm entre si qualquer tipo de semelhança, nem mesmo física.

Conforme a novela avança, todavia, vemos que Jekyll tem cada vez menos controle sobre a erupção de sua personalidade maligna. Nessa identidade cindida, a face mais forte subjuga a mais fraca, e Hyde se torna gradativamente a figura predominante, ao ponto de Jekyll precisar manter sempre à mão uma poção para reverter o processo de metamorfose. Quando se vê subitamente impossibilitado de continuar produzindo tal poção, por falta de matéria-prima, o pouco que ainda resta da sobriedade de Jekyll se decide pela morte por envenenamento - pois só assim conseguirá matar o duplo que tomou conta de si. A cena do suicídio não é efetivamente descrita. Quando o mordomo e um amigo do protagonista invadem seu laboratório, o corpo que encontram - ainda agonizante - sequer é de Jekyll: 
Morte do duplo, morte de si: o suicídio em três narrativas góticas do século 19

Bem no meio daquilo, encontrava-se o corpo de um homem contorcido pela dor e ainda se debatendo. Os dois se aproximaram na ponta dos pés, viraram o corpo de barriga para cima e viram o rosto de Edward Hyde. Vestia roupas largas demais, roupas do tamanho das do doutor; os músculos do rosto ainda se mexiam, o que dava a impressão de que estava vivo, mas a vida já estava se acabando; e pelo pequeno frasco que apertava numa das mãos e pelo forte cheiro de amêndoas no ar, Utterson sabia que olhava para o corpo de um suicida (STEVENSON, 2011b, p. 210).

O "cheiro de amêndoas" remete à composição do cianeto, um veneno popular durante o século 19, principalmente em casos de suicídio. Conforme o desenvolvimento da narrativa, só após a revelação dos manuscritos deixados por Jekyll é que se resolve a trama com um todo e os demais personagens envolvidos enfim descobrem que Jekyll e Hyde, médico e monstro, são a mesma pessoa. Em comentário específico sobre essa obra de Stevenson, Nicole Fernandez Bravo pontua que "o que a novela nos mostra é o fracasso do processo de repressão. Jekyll queria pôr-se a salvo do mal encerrando-o sob uma aparência exterior a si próprio, e é então que ele volta com redobrados poderes" (BRAVO, 2005, p. 277). Apesar das diferenças, assim como no caso de "William Wilson", portanto, também em O estranho caso de Dr. Jekyll e Mr. Hyde a morte do duplo culmina na morte de si.

Segundo Borges (2002, p. 385), essa novela de Stevenson serviria de inspiração a Oscar Wilde para a criação do romance $O$ retrato de Dorian Gray. De fato, as semelhanças são notáveis. Se no conto de Allan Poe e na novela de Stevenson temos a imagem do espelho a revelar, respectivamente ao final e ao início, a figura do duplo, no caso do personagem Dorian Gray o artifício é muito parecido: uma tela pintada por seu amigo, que apresenta seu retrato. Essa revelação também acontece logo no início da narrativa, mas, diferente dos dois casos anteriores, o retrato desempenha papel fundamental ao longo de todo o romance. 
Morte do duplo, morte de si: o suicídio em três narrativas góticas do século 19 Willian André • Ana Paula Oliveira

O fato é que Dorian, na flor de sua juventude, é dono de uma beleza quase hipnotizante, que nunca passa despercebida. Ao ter seu retrato pintado pelo amigo Basil, ele se encanta com a própria imagem e profere o desejo de permanecer para sempre jovem:

"[...] como isso é triste!" Murmurou Dorian Gray, com seus olhos ainda fixos em seu próprio retrato. "Como isso é triste! Deverei envelhecer, e ficar horrível e assustador. Mas este retrato sempre permanecerá jovem. Nunca ficará mais velho do que neste dia em particular de junho... se fosse ao contrário! Se houvesse como eu sempre ficar jovem e o retrato envelhecer! Por isso eu daria qualquer coisa! Sim, não há nada em todo mundo que eu não daria!" (WILDE, 2012, p. 32-33).

Alinhando-se à tendência das outras duas narrativas apresentadas, de lidar com o sobrenatural, o protagonista de Wilde tem seu desejo atendido: ao longo do romance, em um processo gradativo, Dorian percebe que seu retrato vai demonstrando alterações, sem que o mesmo ocorra com sua aparência física. Não há qualquer explicação concreta para o fenômeno: ele simplesmente acontece.

Mas as alterações no quadro não dizem respeito apenas às marcas da idade. Isso porque a pintura não consiste tanto em um retrato do envelhecimento de Dorian, mas sim em um retrato de sua alma/consciência. Assim, por conta de sua beleza estonteante e inalterável, conforme passa cada vez mais a mergulhar em um universo de devassidões - a exemplo de William Wilson e Hyde/ Jekyll -, ele vai notando deformidades na pintura, que gradativamente vai se assemelhando ao retrato literal de um monstro.

A primeira modificação que o quadro sofre é de especial interesse aqui, pois envolve uma situação de suicídio: logo na parte inicial do romance, Dorian se apaixona por Sybil Vane, uma jovem atriz de dezessete anos. Até conhecê-lo, Sybil se dedica às personagens que encarna no palco de forma apaixonada e arrebatada. Todavia, após sentir o "verdadeiro amor", seus sentimentos se vol- 
Morte do duplo, morte de si: o suicídio em três narrativas góticas do século 19 Willian André • Ana Paula Oliveira

tam todos para o novo objeto de seu afeto, o que faz com que suas encenações empalideçam. O trágico da situação é que Dorian não se apaixonara tanto por Sybil, mas sim por sua realização artística no teatro. Dessa forma, ao se deparar com a mudança que a torna uma atriz mediana, que atua desapaixonadamente, ele se sente frustrado e rompe a relação, dirigindo palavras ofensivas à jovem:

\footnotetext{
Eu a amava porque era maravilhosa, porque tinha talento e intelecto, porque compreendia os sonhos dos grandes poetas e dava forma e substância às sombras da arte. Você jogou tudo fora. Você é superficial e estúpida [...] Uma atriz de terceira categoria com um rosto bonito (WILDE, 2012, p. 57).
}

Desiludida com o ocorrido, Sybil acaba por tirar a própria vida. A cena do suicídio não é retratada no romance, vindo ao conhecimento de Dorian no dia seguinte, por meio de seu mentor na vida de devassidão, lorde Henry Wotton (que, por sua vez, ficara sabendo do ocorrido pelos jornais): "Ela engolira alguma coisa por engano, alguma coisa terrível que usam nos teatros, mas era ácido prússico ou alvaiade" (WILDE, 2012, p. 64). Passado o abalo inicial provocado pela notícia, o protagonista suprime mais e mais qualquer tipo de consciência pesada ou ética, e se entrega a uma série de práticas ilícitas e criminosas. Assim como no caso de "O médico e monstro", o ápice dessas práticas em Dorian também envolve um assassinato (de seu antigo amigo Basil, o autor de seu retrato). Quanto à pintura, vai se tornando gradativamente mais grotesca, enquanto a aparência física do protagonista é mantida intacta.

O desfecho do romance é muito parecido com o das outras duas obras anteriores. Em um súbito arroubo de consciência, tentando renegar o monstro que se tornara e se libertar para uma nova vida, Dorian decide destruir o retrato. Usando a mesma faca com que matara seu amigo, apunhala a pintura e a rasga de cima a baixo. No mesmo instante, os criados da casa escutam um grito e, forçando a entrada no quarto pela sacada, encontram a seguinte cena: 
Morte do duplo, morte de si: o suicídio em três narrativas góticas do século 19

Quando entraram, encontraram suspenso à parede um esplêndido retrato de seu patrão como o tinham visto pela última vez, em todo o seu esplendor de uma delicada juventude e beleza. Deitado no chão havia um homem morto, em roupa de gala, com uma faca em seu coração. Ele estava murcho, enrugado e seu semblante era repugnante. Apenas quando examinaram os anéis reconheceram quem era (WILDE, 2012, p. 123).

Novamente, portanto, temos a situação de um personagem que, ao matar seu duplo, acaba matando a si mesmo. Segundo Bravo, o suicídio do personagem efetua "na morte a inversão do superficial e do íntimo. Dorian petrifica-se numa imagem, sem ter alcançado a autoconsciência. A função de advertência, exercida pelo duplo ao ir enfeando, perdeu-se. Dorian luta até o fim contra a interiorização da consciência" (BRAVO, 2005, p. 272).

Retomando o que havíamos dito no início, o duplo atua, em cada uma das três narrativas, como o desencadeador de um elemento sobrenatural. Seja um reflexo da alma ou da consciência, esse elemento sobrenatural existe concretamente no plano da narrativa e exerce grande influência sobre os personagens, deixando-os desestabilizados. Em termos metafóricos, o que se coloca nessas narrativas é o problema da crise da identidade: "A crise da identidade humana faz aceder à aceitação da natureza humana com sua dupla postulação do anjo e da besta" (BRAVO, 2005, p. 278). Para retomar o estado de normalidade - tanto no sentido de destruir o elemento sobrenatural quanto no de se procurar por uma identidade homogênea, unitária - o duplo precisa ser extinto, mas não é possível fazê-lo de outra forma senão por meio do suicídio.

Considerando a importância dessas três narrativas na história da literatura ocidental, é notável o quanto seus temas centrais acabam se relacionando com o desfecho por meio da morte autoinfligida. Nossa justificativa para pensá-las por esse viés deve-se à constatação de que o período em que foram publicadas corresponde a um ponto de grandes mudanças na compreensão do fe- 
Morte do duplo, morte de si: o suicídio em três narrativas góticas do século 19 Willian André • Ana Paula Oliveira

nômeno do autoaniquilamento. Sete anos após a publicação do romance de Oscar Wilde viria a público o livro 0 suicídio: estudo de sociologia (1897), de Émile Durkheim, até hoje considerado um marco nos estudos sobre o assunto por desenvolver uma visão sociológica - que já vinha sendo discutida, por esse mesmo viés, algumas décadas antes, por Marx e Engels. Pouco tempo depois, nos primeiros anos do século 20, Freud fundaria a psicanálise, dedicando também à questão do suicídio alguma atenção. "William Wilson", O estranho caso de Dr. Jekyll e Mr. Hyde, e O retrato de Dorian Gray são escritos, portanto, às vésperas da inauguração de duas novas linhas de estudo sobre a morte voluntária: a sociológica e a psicanalítica.

Já observamos um comentário de Borges sobre a novela de Stevenson ter antecipado o desenvolvimento do conceito de esquizofrenia e acreditamos que a mesma afirmação cabe às outras duas obras. Bravo corrobora essa interpretação, observando que, nas narrativas do século 19 que envolvem o tema do duplo, "o sujeito freudiano dividido aparece na literatura antes de ser teorizado" (BRAVO, 2005, p. 276). Ainda pensando em Freud, cabe aqui também um conceito muito importante cunhado pelo autor: o Unheimliche (inquietante/estranho). Tratando de um sentimento que, sendo familiar, provoca estranhamento, o pai da psicanálise observa que "Unheimliche seria tudo o que deveria permanecer secreto, oculto, mas apareceu" (FREUD, 2010, p. 338). Entendemos que essa também é uma definição intimamente relacionada à erupção do duplo nos textos que estamos analisando.

Em se tratando de sociologia, podemos fazer uma projeção procurando compreender o porquê dessa recorrência de obras tratando o tema do duplo de forma tão parecida, e qual a sua vinculação com a questão do suicídio. Considerando essa possibilidade, abordaremos, nas próximas páginas, mais especificamente o contexto da Era Vitoriana, no qual se inserem as narrativas de Stevenson e Wilde ${ }^{3}$.

\footnotetext{
3 Se bem que, também no aspecto social, "William Wilson" é muito parecido com as obras vitorianas em nosso corpus - e seu protagonista acaba sendo um cosmopolita, viajando não só pela Inglaterra, mas também por vários países da Europa. A maior diferença, então, seria que Allan Poe não vivenciou tão diretamente o contexto vitoriano, como aconteceu com Stevenson e Wilde.
} 
Morte do duplo, morte de si: o suicídio em três narrativas góticas do século 19

Danielle Benyon-Payne publicou, em 2015, um estudo intitulado The Suicide Question in Late Victorian Gothic Fiction: representations of suicide in their historical, cultural and social contexts. A tese em questão apresenta provavelmente o panorama mais abrangente e mais consistente sobre o tema da morte voluntária na literatura da Grã-Bretanha em finais do século 19, inventariando e analisando, sistematicamente, uma série de obras - desde as mais populares até as praticamente desconhecidas. Além do vasto material literário, Benyon-Payne procura estabelecer diálogos com diferentes correntes de estudo que tratavam do suicídio à época (ciências sociais, estatística, ciências naturais, medicina) e, para completar, apresenta também um amplo levantamento de artigos e notícias sobre o assunto, publicados em diversos jornais britânicos durante o período.

Uma das principais questões que a autora levanta é o alto índice de desenvolvimento da sociedade vitoriana: científico, tecnológico, industrial, de imprensa, populacional. Como sempre, trata-se de pensar o longo reinado da Rainha Vitória como uma "faca de dois gumes": de um lado, uma sociedade desenvolvida nos mais diversos setores; do outro, e como consequência, as mazelas das classes mais desfavorecidas da sociedade aumentando de forma gritante (miséria, condições sub-humanas de vida, exploração excessiva do trabalho nas indústrias). Com relação específica ao suicídio, ela pontua uma mudança de perspectiva ocorrida da metade para o final do século 19: a percepção anterior de que a morte voluntária estaria necessariamente ligada às classes sociais mais baixas - quase uma doença inerente ao proletariado, validada inclusive por estudos das ciências naturais de orientação darwiniana - é gradativamente substituída pela percepção de que se trata também (e talvez até muito mais) das classes média e alta (BENYON-PAYNE, 2015, p. 123-124).

Nesse sentido, o aumento dos índices de suicídios passa a ser visto como um efeito direto do desenvolvimento tecnológico, industrial e científico, afetando principalmente os indivíduos que têm acesso aos produtos materiais gerados por esse desenvol- 
Morte do duplo, morte de si: o suicídio em três narrativas góticas do século 19 Willian André • Ana Paula Oliveira

vimento. Vale a pena mencionar aqui, mesmo que rapidamente, outra novela de Stevenson, não contemplada em nosso corpus: $O$ clube do suicídio 4 . Abrindo mão de apresentar detalhes do enredo, observemos apenas o discurso de um personagem, quando ele está apresentando o Clube do Suicídio aos protagonistas da novela:

[...] vivemos na era do conforto, e preciso lhes contar a última palavra em termos de facilidade. Temos compromissos em diferentes lugares, e por isso as ferrovias foram inventadas. Como as ferrovias invariavelmente nos separam de nossos amigos, foram criados os telégrafos, para que pudéssemos nos comunicar à distância com mais rapidez. Até mesmo nos hotéis temos elevadores que nos poupam o trabalho de escalar algumas centenas de degraus. Ora, sabemos que a vida é um palco para bancarmos os tolos pelo tempo que esse papel nos apeteça. $\mathrm{O}$ mundo moderno ainda sentia falta de mais uma comodidade. Um modo decente e fácil de abandonar este palco, a escada dos fundos rumo à liberdade. Ou, como acabei de dizer, a porta privativa da Morte. Isso, meus bons companheiros de rebeldia, é oferecido pelo Clube do Suicídio. (...) Inúmeros companheiros nossos - aqueles que foram se tornando genuinamente fartos da encenação da qual se espera que tomem parte dia após dia passaram a vida impedidos de escapar por causa de apenas um ou dois motivos. Alguns têm famílias que ficariam chocadas ou até se sentiriam responsáveis se a questão se tornasse pública. Outros no íntimo fraquejam e recuam diante das circunstâncias da morte. Ou seja, até certo ponto, é o que eu mesmo experimento. Sou incapaz de encostar uma pistola na cabeça e puxar o gatilho, porque algo mais forte do que eu me impede o gesto. E embora eu abomine a vida não tenho força suficiente em meu corpo para me entregar à morte e dar a vida por encerrada. Para aqueles como eu, e para todos os que anseiam dar adeus a este turbilhão sem um escândalo póstumo, foi criado o Clube do Suicídio (STEVENSON, 2011a, p. 61-62).

4 Ainda que trate, à sua maneira, do tema do duplo, entendemos que $O$ clube do suicídio destoa bastante do tipo de abordagem realizada nos três textos de nosso corpus. 
Morte do duplo, morte de si: o suicídio em três narrativas góticas do século 19 Willian André • Ana Paula Oliveira

A crítica proposta por Stevenson é contundente e se abre em dois caminhos. O primeiro deles está relacionado justamente à ideia do suicídio como consequência de uma sociedade altamente desenvolvida. O personagem chega a mencionar várias das comodidades que o século 19 desenvolveu (e a Inglaterra vitoriana, nesse contexto, era uma das principais referências, tendo inclusive servido de palco para a primeira grande Exposição Universal, em 1851) - ferrovias, telégrafos, elevadores -, para depois inventariar junto a elas a comodidade proposta pelo Clube, que presta serviços àqueles que desejam morrer.

O segundo caminho também está relacionado às inovações contextuais da época, mas desfere uma crítica mais diretamente relacionada a outra face dupla da Era Vitoriana: a moral. Observamos no excerto que o personagem ressalta o fato de o Clube do Suicídio ter como público-alvo "aqueles que foram se tornando genuinamente fartos da encenação da qual se espera que tomem parte dia após dia". Os possíveis motivos dos suicidas são tratados quase com deboche, pois o que realmente importa é o depois: morrer sem causar um "escândalo póstumo", sem deixar, para a família e para a sociedade, motivos de preocupação e vergonha. Esse é o primeiro problema moral a ser pontuado, relacionado a uma sociedade que, sendo altamente desenvolvida, contraditoriamente ainda preserva uma moral retrógrada calcada na imagem social. Quanto ao segundo problema moral, ele se relaciona com uma constatação feita por Benyon-Payne:

Max Nordau relaciona os vícios e a degeneração nas classes média e alta, escrevendo: "se [um homem] é refinado e bem de vida... ele comete pequenos delitos peculiares à classe alta, que tem por objeto não a satisfação de necessidades materiais, mas sim outros tipos de desejo" (NORDAU, 1895, p. 260). Esses "desejos" incluíam apostas, álcool e depravação sexual, e, ao final do século 19, acreditava-se que tais vícios haviam aumentado. O problema, de acordo com Morselli (1881, p. 289), era que o aprimoramento em "civilização" e "conhecimento" levou ao 
Morte do duplo, morte de si: o suicídio em três narrativas góticas do século 19

aumento de necessidades, insatisfação e pessimismo, todos podendo resultar na aquisição de vícios (BENYON-PAYNE, 2015, p. 124 , tradução nossa).

Esse aumento de vícios e necessidades, conforme percepções de Nordau e Morselli comentadas por Banyon-Payne, levam ao aumento de insatisfação e pessimismo, podendo, muitas vezes, resultar em suicídio. Há um reflexo desses sentimentos na menção do personagem de $O$ clube do suicídio àqueles que se tornaram "fartos" da vida. E, retornando a "William Wilson", O estranho caso de Dr. Jekyll e Mr. Hyde, e O retrato de Dorian Gray, parecemos adentrar a mesma questão.

Ao longo de nossas análises, ressaltamos que os protagonistas das três narrativas, sem exceção, dedicavam-se a vícios como aqueles apontados no comentário de Banyon-Payne. Essa “devassidão moral" pode estar relacionada, até certo ponto, ao fato de serem personagens que gozam de um bom status social, tendo farto acesso aos bens que transitam pelas classes mais altas da sociedade. Paradoxalmente, os estratos sociais com maior poder aquisitivo e acesso aos mais variados bens materiais são justamente os que correm mais risco de sentir-se enfadados e adentrar um ciclo vicioso de busca por uma saciedade que nunca poderá ser plenamente suprida. Assim como sugerem tanto Banyon-Payne quanto o personagem de $O$ clube do suicídio, estudiosos da morte voluntária, tais como Erwin Stengel (1964, p. 23) e Alfred Alvarez (1999, p. 108), registram que os índices de suicídios são maiores em agrupamentos sociais mais prósperos e desenvolvidos, em contraponto aos contextos de privação e precariedade material, nos quais os índices são menores. Conforme esse raciocínio, o suicídio poderia ser, em parte, consequência da percepção momentânea de que a busca por novas sensações, transformada em fetichismo, nunca chegará a termo, gerando uma situação insustentável.

Para concluir, ainda precisamos recontextualizar a figura do duplo nessa reflexão de caráter mais social que percorre as últimas páginas - e, assim, uma vez mais, caímos na questão da moral: 
Morte do duplo, morte de si: o suicídio em três narrativas góticas do século 19 Willian André • Ana Paula Oliveira

contraditória por excelência, como já observamos, a Era Vitoriana serve de palco a um conflito entre a evolução de suas tecnologias e o arcaísmo de sua moral. Há muito à disposição de seus cidadãos (daqueles que são abastados financeiramente, pelo menos), mas, ao mesmo tempo, há uma política de cerceamento da busca por muitos prazeres considerados ilícitos.

Em meio a esse fogo cruzado, o cidadão vitoriano alimenta, necessariamente, uma vida dupla: precisa manter sua imagem social para continuar em acordo com os ditames morais; não consegue deixar de se entregar aos prazeres que esses ditames morais the proíbem. De certa forma, essa condição é espelhada nas histórias de William Wilson, Dr. Jekyll e Dorian Gray. Cada um deles se depara, em algum ponto de sua vida, com um outro que é ele mesmo, e que dá vazão às suas vontades mais reprimidas 5 . Se observamos, ao longo da exploração dessas três narrativas, que o duplo atua como uma imagem da alma ou da consciência de seus protagonistas, encerramos nossas reflexões acrescentando que ele também reflete as práticas sociais que a moral da época insistia em suprimir. A impossibilidade de resolver esse impasse da vida dupla leva os personagens ao suicídio.

Um entendimento possível para o desfecho semelhante nas três obras é o de que o autoaniquilamento seria uma forma de "punição" para William Wilson, Dr. Jekyll e Dorian Gray, por conta de seus desvios morais. Em sentido oposto, também é possível entender que o suicídio seria não uma "punição", mas uma "coroação" da vida desviante que levaram os personagens: se considerarmos que a morte autoinfligida era percebida, no século 19, como uma das atitudes mais imorais possíveis, acrescentá-la como ponto final ao percurso de Wilson, Jekyll e Gray pode servir como uma espécie de potencialização de sua devassidão. Acreditamos que ambas as interpretações são válidas, mas não no sentido de que Allan Poe, Stevenson e Wilde tenham pretendido corroborar qualquer tipo de discurso moralizante. Pelo contrário, a percepção

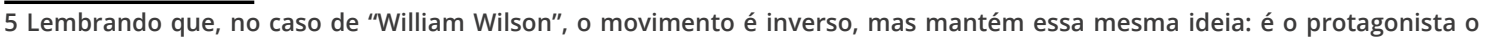
devasso, cabendo ao duplo o papel condizente com a moral social. 
Morte do duplo, morte de si: o suicídio em três narrativas góticas do século 19 Willian André • Ana Paula Oliveira

dos autores parece acentuar uma denúncia dos impasses morais vigentes à época em que produziram suas obras.

Essa leitura de inclinação sociológica não exclui, é claro, a percepção de que o suicídio é, no mais das vezes, um ato majoritariamente individual e subjetivo. No limite, as possibilidades de interpretação que procuramos desenvolver ao longo deste artigo preservam a tensão entre o individual e o social que frequentemente circunda o ato da morte voluntária: uma tensão que começava a florescer justamente no período em que as obras aqui analisadas foram publicadas. Isso mostra como a arte muitas vezes não apenas reflete, mas antecipa nossas reflexões sobre a condição humana sob diversas variáveis. E, em última instância, mostra também que certas obras, por mais que tenham sido debatidas e estudadas ao longo das décadas, ainda mantêm a vitalidade de proporcionar novos olhares e abordagens.

\section{Referências}

ALVAREZ, Alfred. O deus selvagem: um estudo do suicídio. Trad. Sonia Moreira. São Paulo: Companhia das Letras, 1999.

BENYON-PAYNE, Danielle Margaret Ramsey. The Suicide Question in Late Victorian Gothic Fiction: Representations of suicide in their historical, cultural and social contexts. Leicester: University of Leicester, 2015.

BORGES, Jorge Luis. Curso de literatura inglesa. Trad. Eduardo Brandão. Organização, pesquisa e notas: Martín Arias e Martin Hadis. São Paulo: Martins Fontes, 2002.

BRAVO, Nicole Fernandez. O duplo. In: BRUNEL, Pierre (Org.).

Dicionário de mitos literários. 4. ed. Trad. Carlos Sussekind, Jorge Laclette, Maria Thereza Rezende Costa, Vera Whately. Rio de Janeiro: José Olympio, 2005, p. 261-287.

CUDDON, J. A. The Penguin Dictionary of Literary Terms and 
Morte do duplo, morte de si: o suicídio em três narrativas góticas do século 19 Willian André • Ana Paula Oliveira

Literary Theory. London: Penguin, 1998.

FISHER, Benjamin Franklin. Poe and the Gothic Tradition. In: HAYES, Kevin J. (Ed.) The Cambridge Companion to Edgar Allan Poe. Cambridge: Cambridge University Press, 2004, p. 72-91. FREUD, Sigmund. O inquietante. In: FREUD, Sigmund. Obras completas - vol. 14 (1917-1920). Trad. Paulo César de Souza. São Paulo: Companhia das Letras, 2010, p. 328-376.

POE, Edgar Allan. William Wilson. In: POE, Edgar Allan. Histórias extraordinárias. Seleção, Apresentação e Trad. José Paulo Paes. São Paulo: Companhia das Letras, 2008, p. 234-253.

ROAS, David. La amenaza de lo fantástico. In: ROAS, David (Org.). Teorías de lo fantástico. Madrid: Arco/Libros: 2001, p. 7-44. SHELLEY, Mary. Frankenstein. Trad. Márcia Xavier de Brito, Carlos Primati. Ilustrações: Pedro Franz. Rio de Janeiro: DarkSide Books, 2017.

STENGEL, Erwin. Suicide \& Attempted Suicide. Harmondsworth: Penguin, 1964.

STEVENSON, Robert Louis. O clube do suicídio. In: STEVENSON, Robert Louis. $\mathrm{O}$ clube do suicídio e outras histórias. Trad. Andréa Rocha. São Paulo: Cosac Naify, 2011a, p. 49-148.

STEVENSON, Robert Louis. O estranho caso de Dr. Jekyll e Mr. Hyde. In: STEVENSON, Robert Louis. O clube do suicídio e outras histórias. Trad. Andréa Rocha. São Paulo: Cosac Naify, 2011b, p. 149-247.

WILDE, Oscar. O retrato de Dorian Gray. Trad. José Eduardo Ribeiro Moretzsohn. Porto Alegre: L\&PM, 2012. 